\title{
G-Protein-Gated Potassium Channels Containing Kir3.2 and Kir3.3 Subunits Mediate the Acute Inhibitory Effects of Opioids on Locus Ceruleus Neurons
}

\author{
Maria Torrecilla, ${ }^{1}$ Cheryl L. Marker, ${ }^{2}$ Stephanie C. Cintora, ${ }^{2}$ Markus Stoffel, ${ }^{3}$ John T. Williams, ${ }^{1}$ and \\ Kevin Wickman² \\ 1 Vollum Institute, Oregon Health Sciences University, Portland, Oregon 97201, ${ }^{2}$ Department of Pharmacology, University \\ of Minnesota, Minneapolis, Minnesota 55455, and ${ }^{3}$ Laboratory of Metabolic Diseases, Rockefeller University, New York, \\ New York 10021
}

Acute opioid administration causes hyperpolarization of locus ceruleus (LC) neurons. A G-protein-gated, inwardly rectifying potassium $\left(\mathrm{GIRK} / \mathrm{K}_{\mathrm{G}}\right)$ conductance and a cAMP-dependent cation conductance have both been implicated in this effect; the relative contribution of each conductance remains controversial. Here, the contribution of $\mathrm{K}_{\mathrm{G}}$ channels to the inhibitory effects of opioids on LC neurons was examined using mice that lack the $\mathrm{K}_{\mathrm{G}}$ channel subunits Kir3.2 and Kir3.3. Resting membrane potentials of LC neurons in brain slices from Kir3.2 knock-out, Kir3.3 knock-out, and Kir3.2/3.3 double knock-out mice were depolarized by $15-20 \mathrm{mV}$ relative to $\mathrm{LC}$ neurons from wild-type mice. [Met] ${ }^{5}$ enkephalin-induced hyperpolarization and whole-cell current were reduced by $40 \%$ in LC neurons

Opioid agonists elicit a broad spectrum of physiological and behavioral responses in mammals, including analgesia, respiratory depression, tolerance, and addiction (for review, see Law et al., 2000). Opioid effects are mediated by $\mu, \delta$, and $\kappa$ opioid receptors, all three of which stimulate pertussis toxin-sensitive G-proteins $\left(\mathrm{G}_{\mathrm{i} / \mathrm{o}}\right)$. The effects of $\mathrm{G}_{\mathrm{i} / \mathrm{o}}$ activation on effector function include the inhibition of adenylyl cyclase and voltage-gated calcium channels and activation of G-protein-gated, inwardly rectifying potassium $\left(\mathrm{K}_{\mathrm{G}} / \mathrm{GIRK} / \mathrm{Kir} 3\right)$ channels (Law et al., 2000). However, the relative contributions of these and other effectors to the complex responses to opioids are generally unknown and are a matter of controversy in the locus ceruleus (LC) (Williams et al., 2001).

Acute opiate administration leads to a decrease in the firing rate and hyperpolarization of rat LC neurons through the activation of $\mu$ opioid receptors (Pepper and Henderson, 1980; Williams et al., 1982; Williams and North, 1984). The opioid-induced inhibition of LC neurons has been proposed to be attributable to the activation of $\mathrm{K}_{\mathrm{G}}$ conductance (North and Williams, 1985;

\footnotetext{
Received Feb. 5, 2002; revised Feb. 27, 2002; accepted March 1, 2002.

This work was supported by National Institutes of Health Grants 1R01-MH6193 (K.W.) and DA08163 (J.T.W. and M.T.) and by the Pharmaceutical Researchers and Manufacturers of America Foundation (K.W.). M.T. was supported in part by a postdoctoral fellowship from the Basque Government. We thank Dr. D. E. Clapham (Children's Hospital/Howard Hughes Medical Institute, Boston, MA) for generously providing support (NIH Grants R01-54873 and P01 38312) during the generation of the Kir3.3 knock-out mice, and Drs. Veronica Alvarez-Maubecin and Hitoshi Morikawa for helpful comments on this manuscript.

Correspondence should be addressed to Dr. Kenneth Wickman, University of Minnesota, Department of Pharmacology, 6-120 Jackson Hall, 321 Church Street Southeast, Minneapolis, MN 55455. E-mail: wickm002@tc.umn.edu.

Copyright (ㄷ) 2002 Society for Neuroscience $0270-6474 / 02 / 224328-07 \$ 15.00 / 0$
}

from Kir3.2 knock-out mice and by $80 \%$ in neurons from Kir3.2/ 3.3 double knock-out mice. The small opioid-sensitive current observed in LC neurons from Kir3.2/3.3 double knock-out mice was virtually eliminated with the nonselective potassium channel blockers barium and cesium. We conclude that the acute opioid inhibition of LC neurons is mediated primarily by the activation of G-protein-gated potassium channels and that the cAMP-dependent cation conductance does not contribute significantly to this effect.

Key words: GIRK; Kir3.0; opioid receptor; whole-cell recording; addiction; tolerance; locus ceruleus; potassium channel blockers; mouse knock-out; met-enkephalin
Aghajanian and Wang, 1986; Williams et al., 1988; Travagli et al., 1995, 1996). However, other studies have suggested that approximately one-half of the opioid-induced current results from the suppression of a cAMP-regulated, sodium-dependent inward conductance (Wang and Aghajanian, 1987; Alreja and Aghajanian, 1993, 1994, 1995). The lack of highly selective blockers for the channels in question has hindered the clear resolution of this controversy.

$\mathrm{K}_{\mathrm{G}}$ channels are tetramers formed by members of the Kir3/ GIRK subfamily of inwardly rectifying $\mathrm{K}^{+}$channel subunits (Dascal, 1997). Four Kir3 subunits have been identified; three (Kir3.1/GIRK1, Kir3.2/GIRK2, and Kir3.3/GIRK3) are expressed throughout the CNS, including the LC (Karschin et al., 1996; Chen et al., 1997). Although the biophysical properties of $\mathrm{K}_{\mathrm{G}}$ channels are primarily independent of subunit composition, it should be noted that Kir3.1 homotetramers do not form functional channels (Hedin et al., 1996).

Kir3 subunit knock-out mice have revealed important roles for $\mathrm{K}_{\mathrm{G}}$ channels in the brain and heart. Kir3.2 knock-out mice are prone to lethal seizures and display a range of phenotypes related to ethanol-induced behaviors (Signorini et al., 1997). In addition, studies involving Kir3.2 knock-out mice have demonstrated the importance of $\mathrm{K}_{\mathrm{G}}$ channels in the generation of IPSPs in hippocampal and cerebellar neurons (Luscher et al., 1997; Slesinger et al., 1997). Similarly, studies involving Kir3.4 knock-out mice have confirmed the key role of $\mathrm{K}_{\mathrm{G}}$ channels in the vagal regulation of heart rate (Wickman et al., 1998) and have suggested a role for $\mathrm{K}_{\mathrm{G}}$ channels in spatial learning/memory processes (Wickman et al., 2000). 
This study describes the generation of Kir3.3 knock-out and Kir3.2/3.3 double knock-out mice. Opioid-induced hyperpolarization and current in LC neurons from wild-type, Kir3.2 knockout, Kir3.3 knock-out, and Kir3.2/3.3 double knock-out mice were examined to identify the channel(s) mediating the actions of opioids in the LC. Our results demonstrate that the acute opioidinduced inhibition of LC neurons is almost exclusively mediated by potassium-selective channels, and in particular, $\mathrm{K}_{\mathrm{G}}$ channels formed by Kir3.2 and Kir3.3 subunits.

\section{MATERIALS AND METHODS}

Generation of Kir3.3 knock-out mice. A Cre recombinase-based Kir3.3 targeting strategy was designed with the goal of obtaining a parental mouse embryonic stem (ES) cell line that could be further modified to yield ES cell clonal derivatives harboring either a null copy of the mouse Kir3.3 gene or a "floxed" version of the mouse Kir3.3 gene. Cloning and characterization of the mouse Kir3.3 gene has been reported previously (Wickman et al., 2002). Appropriate $5^{\prime}$ and $3^{\prime}$ homology arms surrounding the third mouse Kir3.3 gene were subcloned into a pBluescript-based plasmid containing a neomycin resistance gene (NEO) driven by the mouse phosphoglycerate kinase $1(P G K)$ promoter (kindly provided by M. Picciotto, Yale University, New Haven, CT). The third exon was chosen for targeting because it contains coding sequences for the entire $\mathrm{N}$ terminal, membrane-spanning domains, pore region, and a substantial portion of the $\mathrm{C}$ terminal of Kir3.3. The neomycin resistance cassette was flanked by Cre recombinase recognition sites (loxP sites). The diphtheria toxin gene $(D T A)$ driven by the thymidine kinase promoter was included in the construct as a negative selection element to enrich for homologous recombinants as described previously (Wickman et al., 1998). 129Sv/J embryonic stem cells (Genome Systems, St. Louis, MO) at passage 11 were transfected with the linearized targeting vector as described previously (Wickman et al., 1998). One hundred ninety-six colonies surviving G418 selection $(200 \mu \mathrm{g} / \mathrm{ml}$ active constituent for $10 \mathrm{~d})$ were picked, amplified, and screened by PCR and Southern blotting for the appropriate homologous recombination event (as detected by a predictable shift in mobility of a BamHI fragment) (data not shown). The observed targeting frequency was 8 of $192(4.2 \%)$. One clone carrying the targeted allele was amplified and transfected with a plasmid containing the Cre recombinase gene (kindly provided by L. Nitschke, University of Wurzburg, Wurzburg, Germany) to elicit three possible recombination events (Fig. 1A): (1) loss of NEO cassette and Kir3.3 exon 3 (null allele), (2) loss of NEO cassette only (floxed allele), or (3) loss of Kir3.3 exon 3 and retention of NEO cassette (data not shown). To enrich for subclones harboring either the null allele or the floxed allele, Cre-transfected cells were double-plated and evaluated for G418 sensitivity. Cell lines proliferating in the presence of $200 \mu \mathrm{g} / \mathrm{ml}$ active constituent of G418 were discarded. Two subclones carrying the null allele were used to generate chimeric mice, of which three were able to transmit the mutant allele through the germline.

Generation of Kir3.2/Kir3.3 double knock-out mice. Because Kir3.2 knock-out mice exhibited decreased lifespan and fertility in our experience, the Kir3.2 null allele was bred onto the Kir3.3 knock-out background. In brief, mice heterozygous for the Kir3.2 null allele were bred with Kir3.3 knock-out mice to yield animals heterozygous for both Kir3.2 and Kir3.3 null alleles. Crosses between mice of this genotype were established to generate animals homozygous for the null Kir3.3 allele and heterozygous for the Kir3.2 null allele. Crosses between animals of this genotype were established to generate Kir3.3 knock-out mice that were wild-type, heterozygous, or homozygous null at the Kir3.2 locus. The mice used in this study were genotyped either by Southern blotting or by PCR screening using tail DNA as described previously (Wickman et al., 1998). Specific genotyping information is available on request from the authors.

Brain membrane isolation and immunoblotting. Adult (8-12 weeks) mice were killed by $\mathrm{CO}_{2}$ asphyxiation. Brains were extracted, rinsed in ice-cold PBS, and dissected along the midline. One-half of each brain was subjected to three rounds of homogenization in a buffer containing (in mM): $100 \mathrm{NaCl}, 10$ HEPES, pH 7.5, 2 EDTA, pH 8.0, 1 DTT, and a protease inhibitor cocktail (PIC) containing (in $\mu \mathrm{g} / \mathrm{ml}$ ): 0.35 PMSF, 1.7 aprotinin, 0.7 pepstatin, and 10 leupeptin. After a low-speed centrifugation step $(2200 \times g)$ to remove large debris, supernatants were centrifuged at $200,000 \times g$ for $30 \mathrm{~min}$ to pellet the membrane fraction. Pellets were resuspended in $1 \mathrm{ml}$ of a $2 \%$ SDS solution (prewarmed to $37^{\circ} \mathrm{C}$ ) containing $1 \mathrm{~mm}$ DTT and PIC and then centrifuged for 5 min at $500 \times$ $g$ to remove insoluble contents. Protein concentrations were determined using the Lowry assay after TCA precipitation (Sigma, St. Louis, MO). Immunoblotting was performed using NuPage reagents according to the manufacturer's specifications (Invitrogen, Carlsbad, CA). Equal amounts of protein per well were loaded onto $4-12 \%$ Bis-Tris gradient gels (10 $\mu \mathrm{g} /$ well for the Kir3.1 and Kir3.2 gels and $20 \mu \mathrm{g} /$ well for Kir3.3). Samples were heated to $70^{\circ} \mathrm{C}$ for $10 \mathrm{~min}$ before loading. The NuPage 3 -( $N$-morpholino)propanesulfonic acid running buffer and reducing conditions were used during electrophoresis. Proteins were transferred to Hybond ECL nitrocellulose membranes (Amersham Biosciences, Piscataway, NJ) under reducing conditions. Membranes were blocked for $1 \mathrm{hr}$ using a 5\% milk solution (in distilled water) and cut at $\sim 90 \mathrm{kDa}$ to permit the detection of both the relevant Kir3 subunit (35-70 kDa) and NMDA receptor $(105 \mathrm{kDa})$. Anti-Kir3.1 and Kir3.2 antibodies were purchased (Alomone Labs, Jerusalem, Israel) and used at 1:200 dilutions as specified. The anti-Kir3.3 antibody was used at a 1:300 dilution as described previously (Jelacic et al., 2000). The NMDA $\zeta 1$ receptor antibody (Santa Cruz Biotechnology, Santa Cruz, CA) was used at a 1:100 dilution. Membranes were incubated in primary antibody at $4^{\circ} \mathrm{C}$ overnight, washed once for $15 \mathrm{~min}$ and twice for $5 \mathrm{~min}$ with Tris-buffered saline containing $0.01 \%$ Tween 20 (TBST), exposed to the appropriate peroxidase-conjugated secondary antibody (1:5000-1:8000) for $1 \mathrm{hr}$ at room temperature, and washed again with TBST. Protein bands were revealed using ECL Western blotting detection reagents according to the manufacturer's specifications (Amersham Biosciences, Piscataway, NJ) using BIOMAX MR x-ray film (Kodak, Rochester, NY).

Electrophysiology. Breeding pairs consisting of mice heterozygous for the Kir3.2 or Kir3.3 null allele were established to generate litters consisting of wild-type, heterozygous mutant, and single Kir3 subunit knockout mice. Kir3.2/3.3 double knock-out mice were generated as described above. The electrophysiological experiments described below were performed on all animals in a blinded manner before genotyping. Coronal LC slices from 3- to 4-week-old mice were cut in a Vibratome (slice thickness, $220 \mu \mathrm{m})$, transferred to a recording chamber, and superfused with warmed $\left(37^{\circ} \mathrm{C}\right)$ physiological saline solution containing (in mM): 125 $\mathrm{NaCl}, 2.5 \mathrm{KCl}, 1 \mathrm{MgCl}_{2}, 26 \mathrm{NaH}_{2} \mathrm{CO}_{3}, 1.25 \mathrm{NaH}_{2} \mathrm{PO}_{4}, 11$ glucose, 2.4 $\mathrm{CaCl}_{2}$, and bubbled with $95 \% \mathrm{O}_{2}$ and $5 \% \mathrm{CO}_{2}, \mathrm{pH} 7.4(295 \mathrm{mOsm} / \mathrm{kg})$. Cells were visualized using an upright microscope with infrared optics, and recordings were made with patch pipettes (1-4 M $\Omega$ ) containing (in $\mathrm{mm}$ ): 115 potassium methylsulfate, $20 \mathrm{KCl}, 1.5 \mathrm{MgCl}_{2}, 0.1$ EGTA, 5 HEPES, $2 \mathrm{Mg}$-ATP, $0.5 \mathrm{Na}$-GTP, and 10 creatine phosphate, $\mathrm{pH} 7.4$ (280 $\mathrm{mOsm} / \mathrm{kg}$ ). To record inward currents through voltage-gated calcium channels, $\mathrm{CsCl}$ was substituted for potassium methylsulfate and the external solution contained $1 \mathrm{~mm} \mathrm{BaCl}_{2}$ and $300 \mathrm{~nm}$ tetrodotoxin (Alomone Labs). [Met] ${ }^{5}$-enkephalin (ME; Sigma) and solutions were perfused onto the brain slices by gravity flow. Whole-cell recordings were detected with an Axopatch-1D (Axon Instruments, Foster City, CA), filtered at $5 \mathrm{kHz}$, and digitized with an ITC-16 Computer Interface (InstruTech, Port Washington, NY). Data were sampled at $10 \mathrm{kHz}$ with Axograph 4.5 software (Axon Instruments). ME-induced currents were measured in voltage-clamp mode with the membrane potential held at $-60 \mathrm{mV}$. Current-voltage $(I-V)$ relationships were obtained by stepping the membrane potential from -50 to $-130 \mathrm{mV}$ in $-10 \mathrm{mV}$ increments (100 msec per step). Current carried by calcium/barium was evoked by stepping from -60 to $-20 \mathrm{mV}$ every $15 \mathrm{sec}$ for $100 \mathrm{msec}$. Cells in which the calcium/barium current failed to recover to within $10 \%$ of the original level after ME washout were excluded from consideration. The voltage measurements made in current-clamp mode were corrected for the liquid junction potential $(3.3 \mathrm{mV})$ calculated with the program JPCalc (Axon Instruments) (Barry, 1994). Data are presented as means \pm SEM. All statistical comparisons were made using Student's $t$ test (unpaired or paired); $p<0.05$ was considered to be the level of significance.

\section{RESULTS}

Previous studies have suggested that Kir3.1, Kir3.2, and Kir3.3 genes are expressed in the rodent LC (Karschin et al., 1996; Chen et al., 1997). Because Kir3.1 is incapable of forming functional $\mathrm{K}_{\mathrm{G}}$ channels in the absence of other Kir3 subunits (Hedin et al., 1996), and given the lack of evidence for Kir3.4 gene expression in the LC (Karschin et al., 1996; Wickman et al., 2000), we hypothesized that simultaneous ablation of Kir3.2 and Kir3.3 




B
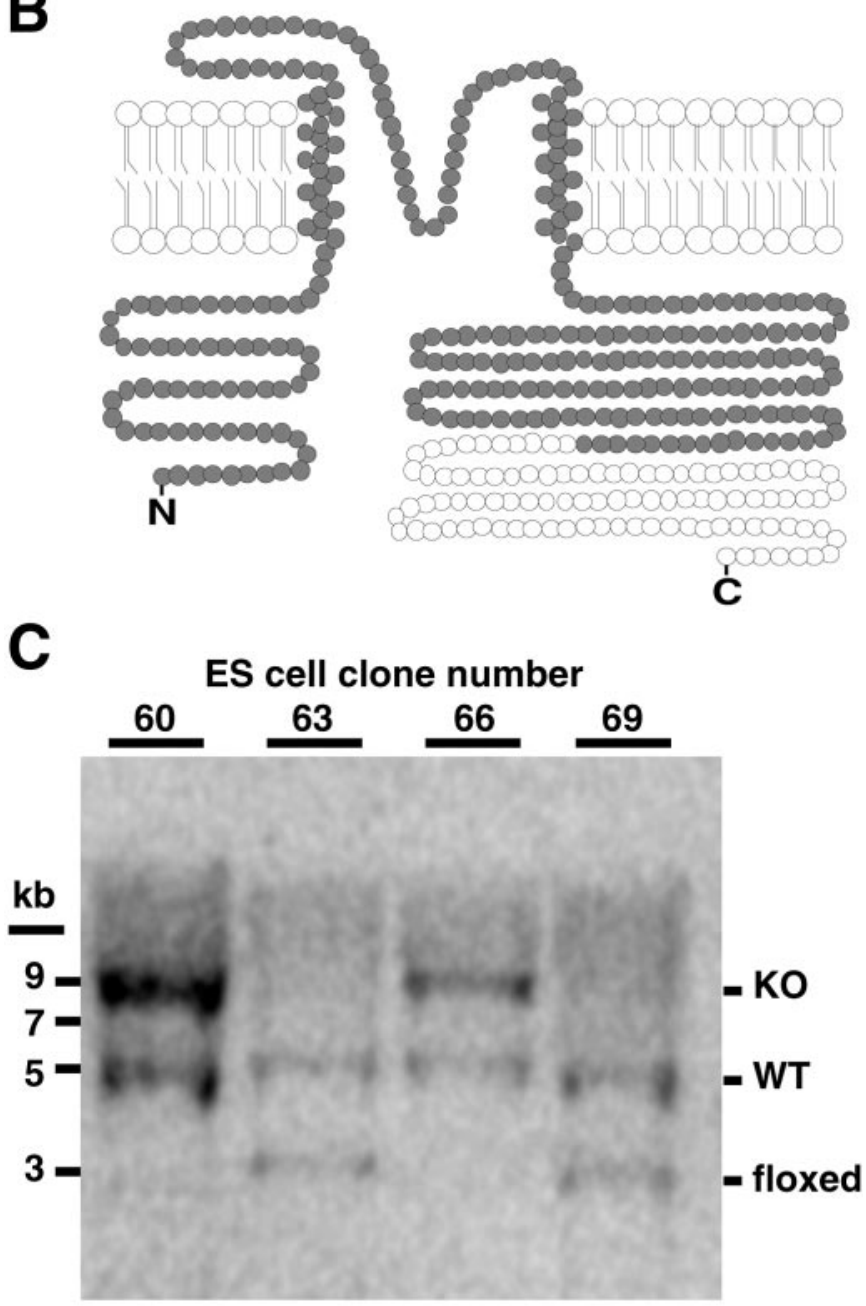

Figure 1. Generation of Kir3.3 knock-out mice. A, Depictions of the mouse Kir3.3 gene, targeting vector, and recombination events. Kir3.3 exons are represented as black rectangles. Vertical arrows indicate the positions of loxP sites. $B, B a m \mathrm{HI}$ restriction enzyme site; $N E O$, neomycin resistance gene cassette; $D T A$, diphtheria toxin gene cassette. $B$, Predicted membrane topology of the Kir3.3 subunit. The domain of shaded circles represents the coding sequence eliminated in the constitutive null Kir3.3 gene. $N$, N-terminal end of the Kir3.3 subunit; $C, \mathrm{C}$-terminal end of the genes would be sufficient, and perhaps necessary, to eliminate all $\mathrm{K}_{\mathrm{G}}$ current in the LC. The generation of Kir3.2 knock-out mice has been described previously (Signorini et al., 1997). We used a modified Cre-loxP targeting strategy for the Kir3.3 gene to permit the generation of tissue-specific and/or conditional Kir3.3 knockout mice in future studies (Fig. 1A) (Picciotto and Wickman, 1998). Exon 3 was chosen for targeting because it contains the coding sequence for most of the key functional domains of the Kir3.3 subunit, including the pore and membrane-spanning domains, the entire $\mathrm{N}$ terminal, and the translation initiation codon (Fig. 1B) (Wickman et al., 2002). Distinct embryonic stem-cell lines were generated that harbored either a constitutive null or a floxed version of the mouse Kir3.3 gene (see Materials and Methods). Wild-type, null, and floxed versions of the Kir3.3 gene were distinguished using Southern blotting (Fig. 1C). For the purpose of this study, ES cells harboring the constitutive null allele were used to generate chimeric mice, and ultimately, constitutive Kir3.3 knock-out mice.

No visible differences between wild-type and Kir3.3 knock-out siblings were discerned related to size or growth, feeding behavior, grooming, responses to visual and sound cues, and coordination (data not shown). Both Kir3.3 knock-out male and female mice are fertile, and breeding pairs yielded normal litter sizes. Lifespan was unaffected by the lack of Kir3.3, and the animals did not exhibit a propensity for spontaneous and lethal seizures, unlike their Kir3.2 knock-out counterparts (Signorini et al., 1997). Analysis of crosses between Kir3.3 heterozygous parent mice revealed the following distribution of males (205 total: $17.1 \%$ wild-type, $54.6 \%$ heterozygous, and $28.3 \%$ knock-out) and females (174 total: $23.6 \%$ wild-type, $50.6 \%$ heterozygous, and $25.8 \%$ knock-out). Although trends toward gender $\left(p=0.41 ; \chi^{2}\right.$ test) and genotype ( $p=0.19 ; \chi^{2}$ test, males) biases were observed in our sample population, neither difference reached statistical significance. Because both male and female Kir3.3 knock-out mice are fertile, we crossed the Kir3.2 null allele onto the Kir3.3 knock-out background (see Materials and Methods). Double knock-out mice were viable and appeared normal, although they experienced spontaneous, lethal seizures between 2 and 8 months of age.

Western blots of brain membrane fractions taken from wildtype, Kir3.2 knock-out, Kir3.3 knock-out, and Kir3.2/3.3 double knock-out mice confirmed the success of the gene-targeting events (Fig. 2). Bands corresponding to Kir3.2 and Kir3.3 are absent in mice of the appropriate genotypes. Interestingly, the loss of either Kir3.2 or Kir3.3 each had little effect on the other, but did result in decreased levels of Kir3.1. In particular, the level of heavily glycosylated Kir3.1 protein decreased significantly in both the Kir3.2 and Kir3.3 knock-outs; it virtually disappeared in the Kir3.2/3.3 double knock-out mice. Similar findings have been reported previously in the heart and brain (Signorini et al., 1997; Wickman et al., 1998).

Kir3.3 subunit. $C$, Southern blot analysis of ES cell clones derived after transfection of an ES cell line carrying the targeted Kir3.3 allele with the Cre recombinase gene. Cre-transfection promoted the excision of DNA found between two loxP sites. G418 sensitivity was used to screen for the transfected cells that lacked the NEO cassette. Genomic DNA from G418-sensitive clones was digested with BamHI and probed with a radiolabeled fragment corresponding to the striped rectangle shown in $A$. Several derivatives harboring the constitutive null [knock-out $(K O)]$ and floxed versions of the Kir3.3 gene were isolated; for this study, chimeric animals were generated using cells from lines 60 and 66. WT, Wild-type. 


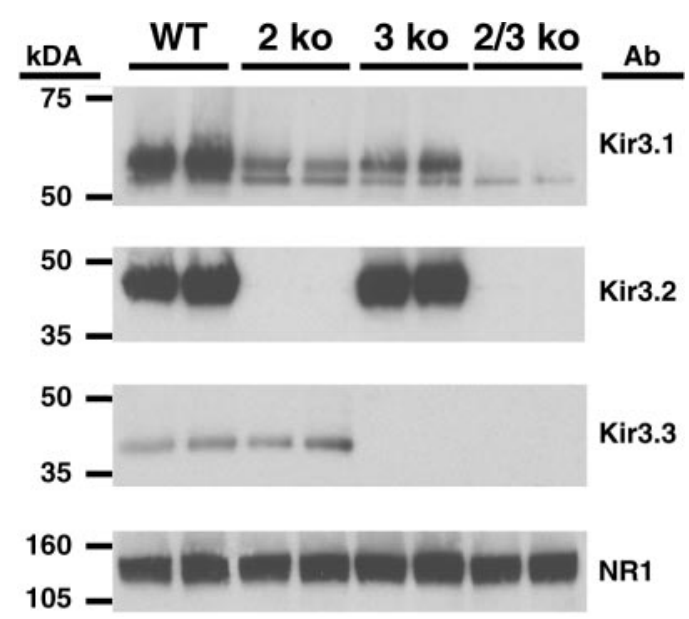

Figure 2. Kir3 protein levels in wild-type and knock-out mouse brains. Membrane proteins from wild-type $(W T)$, Kir3.2 knock-out $(2 \mathrm{ko})$, Kir3.3 knock-out (3 ko), and Kir3.2/3.3 double knock-out (2/3 ko) mouse brains were electrophoresed and probed using anti-Kir3 antibodies. Loading consistency was evaluated using an anti-NMDA receptor subunit (NR1) antibody. Kir3.1 appears as a doublet, with the two bands representing differentially glycosylated versions of the core polypeptide (Krapivinsky et al., 1995). Note that the heavily glycosylated form of Kir3.1 is most affected by the ablation of Kir3.2 and/or Kir3.3. $A b$, Primary antibody.

To determine whether $\mathrm{K}_{\mathrm{G}}$ channel gating contributes to the resting properties of LC neurons, we measured resting membrane potentials in coronal brain slices taken from wild-type and Kir3 knock-out mice. To improve the quality of the voltage/space clamp, thin $(220 \mu \mathrm{m})$ coronal sections were used. Previous studies had shown that LC neurons recorded in coronal sections had reduced resting conductances and improved space-clamp characteristics attributable to the severing of dendrites that project in the horizontal axis (Travagli et al., 1996). The average resting membrane potential of LC neurons from wild-type mice, measured in current-clamp mode, was $-60.2 \pm 1.0 \mathrm{mV}$, similar to previous observations in rat LC neurons (Williams et al., 1982, 1988). In contrast, the resting membrane potential was depolarized by $15-20 \mathrm{mV}$ in LC neurons from each of the Kir3 knock-out mice tested (Fig. 3).

Application of $30 \mu \mathrm{M}$ ME hyperpolarized wild-type LC neurons by $13 \pm 1.5 \mathrm{mV}(n=7)$ (Figs. $4 A, 5 A)$ and induced an outward current of $62 \pm 3 \mathrm{pA}(n=49)$ at $-60 \mathrm{mV}$ in $2.5 \mathrm{~mm}$ $\left[\mathrm{K}^{+}\right]_{\text {out }}$ (Figs. $4 B, C, 5 B$ ). The reversal potential of the MEinduced current was slightly more negative than that predicted by the Nernst equation $(-111 \pm 2 \mathrm{mV} ; n=49)$ (Fig. 4D) (Nernst prediction $=-106 \mathrm{mV})$. When $\left[\mathrm{K}^{+}\right]_{\text {out }}$ was increased to $6.5 \mathrm{~mm}$, the reversal potential shifted to $-89 \pm 4 \mathrm{mV}(n=20)$ (Fig. $4 D)$, indicating that the ME-induced current in mouse LC neurons was mediated primarily by an increase in potassium conductance.

In LC neurons from Kir3.2 knock-out mice, the average MEinduced current $(37 \pm 3 \mathrm{pA} ; n=41)$ and hyperpolarization $(7 \pm$ $2 \mathrm{mV} ; n=7)$ were significantly reduced relative to wild-type controls (Fig. 5). In LC neurons from Kir3.2/3.3 double knock-out mice, the ME-induced hyperpolarization $(2 \pm 1 \mathrm{mV} ; n=12)$ and outward current $(13 \pm 2 \mathrm{pA} ; n=44)$ were barely detectable. These findings indicate that the opioid-induced hyperpolarization of LC neurons is mediated predominantly by the activation of $\mathrm{K}_{\mathrm{G}}$ channels formed by Kir3.2 and/or Kir3.3 subunits.

No significant differences were detected in the ME-induced hyperpolarization or current in LC neurons from wild-type,



Figure 3. Average resting membrane potentials of LC neurons from wild-type $(-60.2 \pm 1.0 \mathrm{mV}), \mathrm{Kir} 3.3$ knock-out $(3 \mathrm{ko})(-36.9+4.6 \mathrm{mV})$, Kir3.2 heterozygous $(2$ het $)(-45.2 \pm 2.7 \mathrm{mV})$, Kir3.2 heterozygous Kir3.3 knock-out $(2$ het $/ 3 \mathrm{ko})(-40.4 \pm 2.0 \mathrm{mV}), \operatorname{Kir} 3.2$ knock-out $(2 \mathrm{ko})$ $(-45.5 \pm 3.2 \mathrm{mV})$, and Kir3.2/3.3 double knock-out $(2 / 3 \mathrm{ko})(-38.8 \pm 2.9$ $\mathrm{mV}$ ) mice. The number of independent experiments for each group is shown at the top of each column; values shown are means \pm SEM. ${ }^{*} p<$ 0.001 (unpaired two-tailed $t$ test).
A

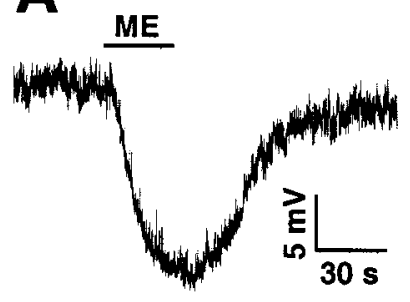

C

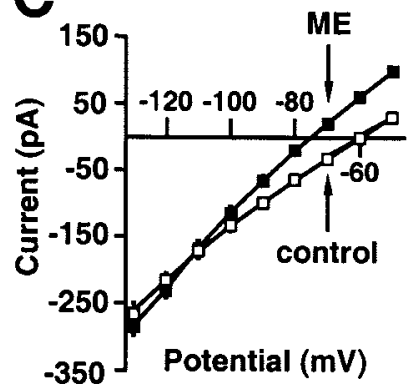

B
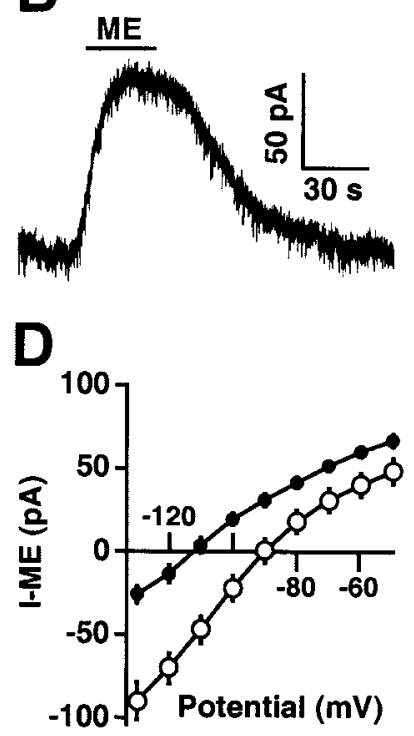

Figure 4. Effect of ME $(30 \mu \mathrm{M})$ on LC neurons in coronal brain slices from wild-type mice. Representative recordings of the hyperpolarization $(A)$ and outward current $(B)$ induced by a brief application of $\mathrm{ME}$ in an LC neuron from a wild-type mouse are shown. $C$, Whole-cell $I-V$ relationships in LC neurons before (control; open squares) and during the perfusion of $\mathrm{ME}$ ( filled squares). $D, I-V$ plots of the ME-induced current (I-ME) in $2.5 \mathrm{~mm}$ ( filled circles) and $6.5 \mathrm{~mm}$ (open circles) extracellular potassium. I-ME was calculated by subtracting the current obtained before ME application from the current obtained in the presence of ME. The reversal potential for I-ME was $-111 \pm 2.1 \mathrm{mV}$ in $2.5 \mathrm{~mm}$ bath potassium and $-89 \pm 4.1 \mathrm{mV}$ in $6.5 \mathrm{~mm}$ bath potassium. The reversal potentials were corrected for the liquid junction potential $(+3.3 \mathrm{mV})$. The holding potential was $-60 \mathrm{mV}$. Values shown are means \pm SEM. 
A
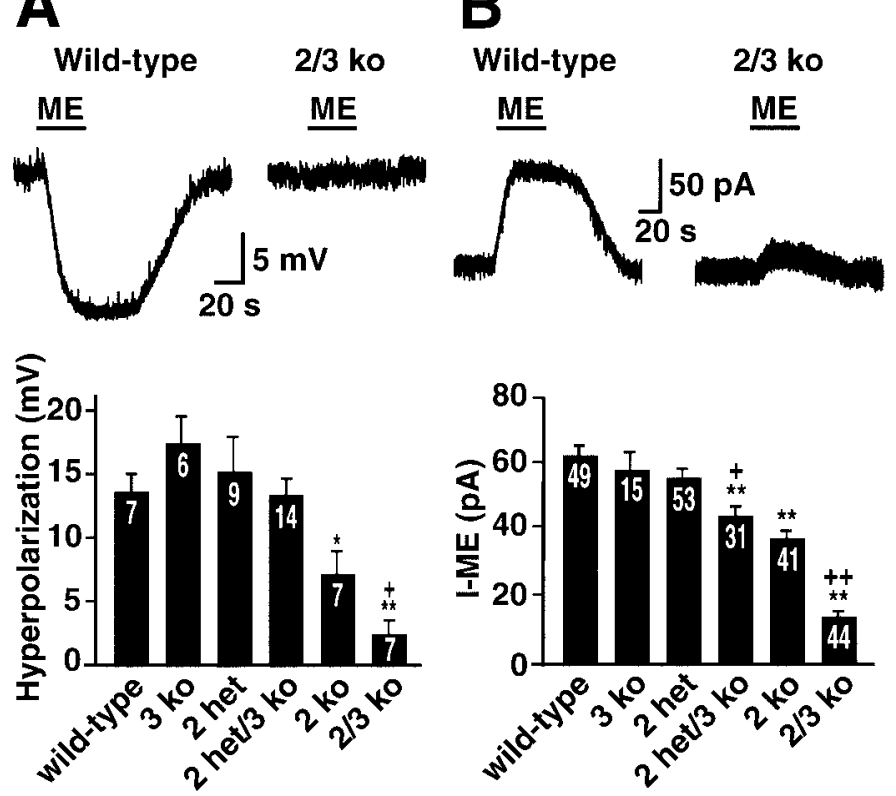

Figure 5. Summary of the ME-induced effects observed in LC neurons from wild-type and Kir3 knock-out mice. $A$, Individual traces and summary bar graphs representing the hyperpolarization observed in LC neurons from wild-type and Kir3 knock-out mice during application of 30 $\mu \mathrm{M}$ ME. In neurons from Kir3.2 knock-out and Kir3.2/3.3 double knockout mice, the hyperpolarizing effect of $\mathrm{ME}$ was smaller than in wild-type mice $\left({ }^{*} p<0.05 ; * * p<0.01\right)$. Statistically significant differences were also observed between the Kir3.2 knock-out and Kir3.2/3.3 double knock-out groups $\left({ }^{+} p<0.05\right)$. $B$, Individual traces and summary bar graphs representing the amplitudes of the ME-induced $(I-M E)$ current in LC neurons from wild-type and Kir3 knock-out mice. The holding potential was -60 $\mathrm{mV}$. ME-induced currents observed in Kir3.2 heterozygous/Kir3.3 knock-out (2 het/3 ko), Kir3.2 knock-out $(2 \mathrm{ko})$, and Kir3.2/3.3 double knock-out $(2 / 3 \mathrm{ko})$ neurons were significantly reduced relative to LC neurons from wild-type mice $(* * p<0.01)$. Moreover, ME-induced currents observed in Kir3.2 knock-out and Kir3.2/3.3 double knock-out mice were significantly different $\left({ }^{++} p<0.01\right)$, as were currents observed in Kir3.2 heterozygous/Kir3.3 knock-out ( $3 \mathrm{ko}$ ) and Kir3.2 heterozygous (2 het) groups $\left({ }^{+} p<0.05\right)$. The number of independent experiments for each group in $A-C$ is shown at the top of each column. Values shown are means \pm SEM.

Kir3.3 knock-out, and Kir3.2 heterozygous mice (Fig. 5). However, a small but significant difference in opioid-induced current was observed between neurons from Kir3.2 heterozygous (54 \pm 3 $\mathrm{pA} ; n=53)$ and Kir3.2 heterozygous/Kir3.3 knock-out (43 \pm 4 pA; $n=31$ ) mice (Fig. 5B). Thus, the functional contribution of Kir3.3 to opioid effects in the LC was not observed when two functional Kir3.2 alleles were present, but it was detected in the absence of one or both Kir3.2 alleles.

The residual ME-induced current observed in Kir3.2/3.3 double knock-out mice was voltage independent in the range tested $(-130$ to $-50 \mathrm{mV})$ and was not significantly altered by increasing the extracellular potassium to $6.5 \mathrm{~mm}$ (Fig. 6A). In LC neurons from a single Kir3.2/3.3 double knock-out animal, replacement of potassium with cesium in the pipette solution and the addition of barium $(1 \mathrm{~mm})$ to the bath was correlated with a reduction in ME-induced current at $-60 \mathrm{mV}$ from $10.0 \pm 1.4$ to $4.4 \pm 1 \mathrm{pA}$ (Fig. 6B,C). The effect of cesium and barium strongly suggests that the residual conductance in LC neurons from Kir3.2/3.3 knock-out mice was carried by potassium-selective ion channels. However, the unusual $I-V$ relationship, lack of effect of increased
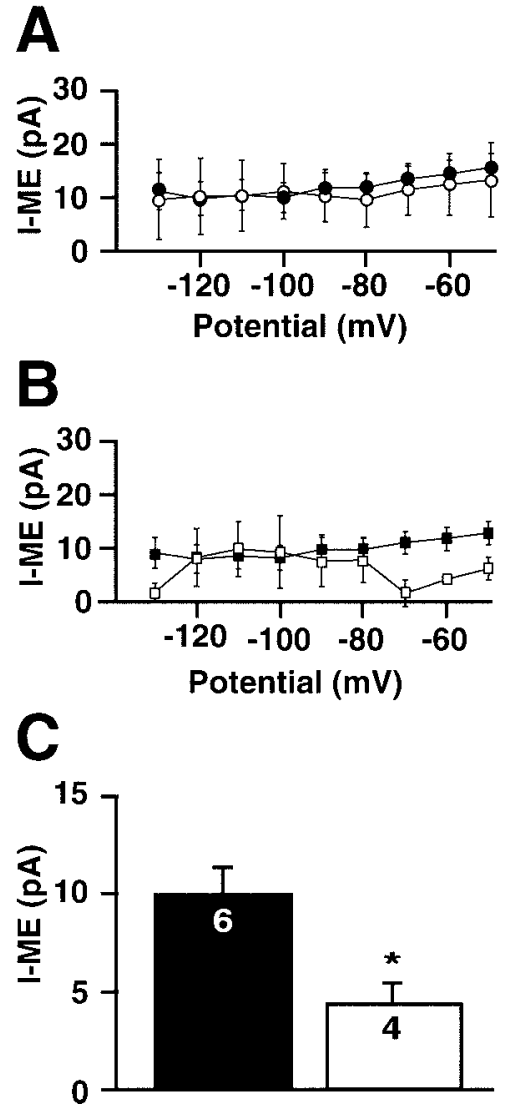

Figure 6. Reduction of the ME-induced current in LC neurons from Kir3.2/3.3 double knock-out mice. $A, I-V$ relationship of ME-induced current $(I-M E)$ in $2.5 \mathrm{~mm}(n=44$; open circles $)$ and $6.5 \mathrm{~mm}(n=6$; filled circles) bath potassium. $B$, With a cesium-based pipette solution and by adding barium (1 $\mathrm{mm})$ to the bath solution, I-ME in LC neurons from Kir3.2/3.3 double knock-out mice decreased between $-80 \mathrm{mV}$ and -50 $\mathrm{mV}$ (open squares) compared with currents measured in cesium- and barium-free conditions ( filled squares). The $I-V$ plots were obtained from neurons from the same double knock-out mouse. $C$, Summary of the experiments shown in $B$ displaying I-ME at $-60 \mathrm{mV}$ in the absence $(n=$ 6; filled bar) and presence $(n=4$; open bar) of barium and cesium. Values shown are means \pm SEM. ${ }^{*} p<0.05$.

extracellular potassium, and variability of the blockage of the current by barium and cesium suggest that an additional minor conductance(s) and/or space-clamp problems contributed to the recorded currents.

The reductions in ME-induced outward current observed in the Kir3 knock-out mice could result from alterations in the function and/or expression levels of other components of the opioid signaling cascade, including the $\mu$ opioid receptor itself and $\mathrm{G}_{\mathrm{i} / \mathrm{o}} \mathrm{G}$-proteins. To examine this possibility, the ME-induced inhibition of calcium current was measured in wild-type and Kir3 knock-out mice. Depolarizing pulses from -60 to $-20 \mathrm{mV}$ consistently produced an inward current carried by calcium and barium in LC neurons from mice of all genotypes tested (Fig. 7A). Although poor space clamp did affect the measurement of calcium currents in the brain slices, as evidenced by sustained inward currents after the voltage step, $30 \mu \mathrm{M}$ ME produced a consistent inhibition of the evoked inward current that was equivalent across all genotypes tested (Fig. 7B). Thus, the reductions in MEinduced currents in Kir3 knock-out mice did not result from a disruption of opioid signal transduction. 

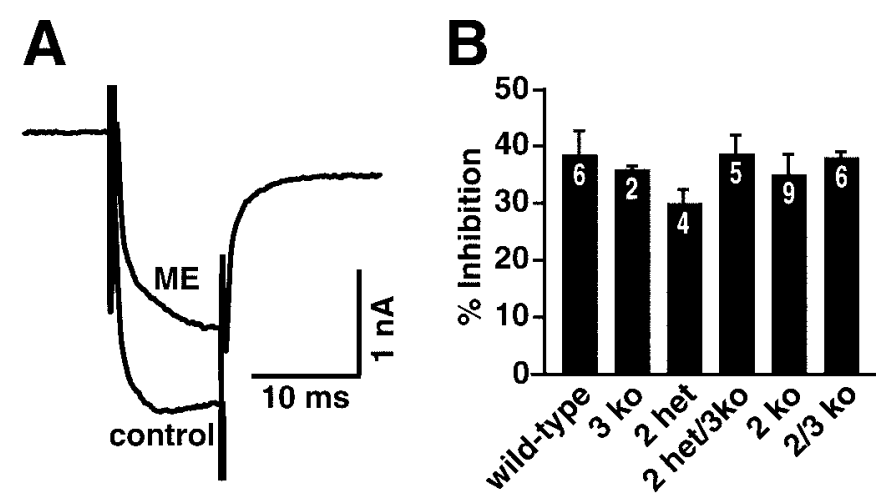

Figure 7. The opioid-induced inhibition of voltage-gated calcium channels is normal in LC neurons from Kir3 knock-out mice. $A$, Example of the inward calcium/barium current elicited by a voltage step from -60 to $-20 \mathrm{mV}$ in an LC neuron from a Kir3.2/Kir3.3 double knock-out mouse (control), and its inhibition during ME perfusion. $B$, Summary of the calcium/barium current inhibition by ME observed in wild-type and Kir3 knock-out mice. Values shown are means \pm SEM, and the number of cells tested in each group shown at the top of each column. 3 ko, Kir3.3 knock-out; 2 het, Kir3.2 heterozygous; 2 het/3 ko, Kir3.2 heterozygous/ Kir3.3 knock-out; 2 ko, Kir3.2 knock-out; 2/3 ko, Kir3.2/3.3 double knock-out.

\section{DISCUSSION}

The main purpose of this study was to identify the mechanism(s) underlying the acute opioid inhibition of LC neurons. We hypothesized that by eliminating the formative subunits of neuronal $\mathrm{K}_{\mathrm{G}}$ channels, we could indirectly measure the contribution of $\mathrm{K}_{\mathrm{G}}$ channels to acute opioid effects in the LC and directly measure residual opioid-sensitive currents in isolation. Our results show that opioid-induced outward currents are reduced by $>80 \%$ in LC neurons from Kir3.2/3.3 double knock-out mice relative to wild-type controls. Furthermore, most of the residual opioidsensitive current was eliminated by cesium and barium, suggesting that this current is carried by potassium-selective channels. It is possible that Kir3.4 expression below the level of detection could explain this small component of the opioid-induced current in the LC. Alternatively, this component of the conductance could result from the opioid-dependent modulation of voltagegated potassium channels, as has been shown in other neurons (Wimpey and Chavkin, 1991).

A small opioid-sensitive current $(\sim 4 \mathrm{pA}$ at $-60 \mathrm{mV})$ that was not blocked by barium and cesium was recorded in neurons from Kir3.2/3.3 double knock-out mice. Primarily because of its small magnitude, we did not characterize this current further. It is possible that this current is the opioid-sensitive, cAMP-activated, inward cation current described previously (Alreja and Aghajanian, 1993, 1994, 1995). That current was proposed to account for $\sim 50 \%$ of the total current induced by acute opioid administration in rat LC neurons; it is of particular interest in light of the well characterized upregulation of adenylyl cyclase that occurs after long-term morphine treatment (Nestler, 2001). The increased excitability of LC neurons in animals treated for a long period with morphine has been proposed to reflect the upregulation of adenylyl cyclase and corresponding increase in the cAMPactivated cation conductance (Kogan et al., 1992; Lane-Ladd et al., 1997; Ivanov and Aston-Jones, 2001). However, the presence of this current in LC neurons has been the subject of considerable controversy (Oleskevich et al., 1993; Travagli et al., 1995, 1996; Osborne and Williams, 1996). Although the present results do not rule out a contribution of the cAMP-activated cation current in morphine-treated animals, it is clear that the role of this conductance in the acute actions of opioids in the LC is limited.

Substance $\mathrm{P}$ was shown previously to decrease resting $\mathrm{K}_{\mathrm{G}}$ / GIRK conductance in cultured LC neurons (Velimirovic et al., 1995). Our study provides additional evidence that $\mathrm{K}_{\mathrm{G}}$ channels, and specifically channels formed by Kir3.2 and Kir3.3 subunits, contribute to the resting membrane potential of LC neurons. Indeed, the average resting membrane potentials of LC neurons from all of the Kir3 subunit knock-out mice tested were significantly depolarized relative to the average resting membrane potential of wild-type LC neurons. The observed effects on resting membrane potential are particularly intriguing for the Kir3.3 knock-out and Kir3.2 heterozygous mice, because we observed no significant effect on opioid-induced currents and hyperpolarization in LC neurons from these animals. These findings suggest that distinct populations of $\mathrm{K}_{\mathrm{G}}$ channels contribute to setting the resting membrane potential and to $\mu$ opioid receptor-coupled currents in LC neurons.

The existence of distinct populations of $\mathrm{K}_{\mathrm{G}}$ channels in $\mathrm{LC}$ neurons could also explain the differential impact of Kir3.2 and Kir3.3 ablation on opioid-induced currents. We observed that the ME-induced current was unaffected in Kir3.3 knock-out mice, was significantly reduced in neurons from the Kir3.2 single knock-out mice, and was virtually absent in neurons from double knock-out mice relative to wild-type LC neurons. One explanation for these observations is that Kir3.2-containing channels mediate $\mu$ opioid receptor effects in wild-type LC neurons and that Kir3.3 can provide partial functional compensation in neurons that lack Kir3.2. It is also possible that Kir3.2 confers a stronger functional association between $\mathrm{K}_{\mathrm{G}}$ channels and $\mu$ opioid receptors than does Kir3.3. Indeed, a greater degree of overlap in the subcellular distributions of $\mu$ opioid receptors and Kir3.2-containing channels (compared with Kir3.3-containing channels) could explain our findings. Clarification of these issues will await the development of high-affinity, Kir3 subunit-specific probes, a task made difficult by the structural similarities of the four Kir3 subunits.

We conclude that potassium-channel activation is primarily responsible for the opioid-induced current and hyperpolarization observed in mouse LC neurons and that $\mathrm{K}_{\mathrm{G}}$ channels composed of Kir3.2 and Kir3.3 mediate most of this effect. This study demonstrates that knock-out mice can be used to dissect the complex effects of opioid agonists on intracellular effector activity. Kir3 subunit knock-out mice should prove useful for examining the alterations in LC neurons that accompany long-term opioid administration, for examining the contribution of $\mathrm{K}_{\mathrm{G}}$ channels to LC excitability and regulation of central noradrenergic tone, and for characterizing the cellular and synaptic adaptations that accompany a variety of behavioral states, as well as mood disorders and depression (Ressler and Nemeroff, 1999).

\section{REFERENCES}

Aghajanian G, Wang Y-Y (1986) Pertussis toxin blocks the outward currents evoked by opiate and alpha(2)-agonists in locus coeruleus neurons. Brain Res 371:390-394.

Alreja M, Aghajanian G (1993) Opiates suppress a resting sodiumdependent inward current and activate an outward potassium current in locus ceruleus neurons. J Neurosci 13:3525-3532.

Alreja M, Aghajanian G (1994) QX-314 blocks the potassium but not the sodium-dependent component of the opiate response in locus coeruleus neurons. Brain Res 639:320-324.

Alreja M, Aghajanian G (1995) Use of the whole-cell patch-clamp method in studies on the role of cAMP in regulating the spontaneous firing of locus coeruleus neurons. J Neurosci Methods 59:67-75.

Barry PH (1994) JPCalc, a software package for calculating liquid junc- 
tion potential corrections in patch-clamp, intracellular, epithelial and bilayer measurements and for correcting junction potential measurements. J Neurosci Methods 51:107-116.

Chen SC, Ehrhard P, Goldowitz D, Smeyne RJ (1997) Developmental expression of the GIRK family of inward rectifying potassium channels: implications for abnormalities in the weaver mutant mouse. Brain Res 778:251-264.

Dascal N (1997) Signalling via the $\mathrm{G}$ protein-activated $\mathrm{K}^{+}$channels. Cell Signal 9:551-573.

Hedin KE, Lim NF, Clapham DE (1996) Cloning of a Xenopus laevis inwardly rectifying $\mathrm{K}^{+}$channel subunit that permits GIRK1 expression of $\mathrm{I}_{\mathrm{KACh}}$ currents in oocytes. Neuron 16:423-429.

Ivanov A, Aston-Jones G (2001) Local opiate withdrawal in locus coeruleus neurons in vitro. J Neurophysiol 85:2388-2397.

Jelacic TM, Kennedy ME, Wickman K, Clapham DE (2000) Functional and biochemical evidence for $\mathrm{G}$-protein-gated inwardly rectifying $\mathrm{K}^{+}$ (GIRK) channels composed of GIRK2 and GIRK3. J Biol Chem 275:36211-36216.

Karschin C, Dissmann E, Stuhmer W, Karschin A (1996) IRK(1-3) and GIRK(1-4) inwardly rectifying $\mathrm{K}^{+}$channel mRNAs are differentially expressed in the adult rat brain. J Neurosci 16:3559-3570.

Kogan JH, Nestler EJ, Aghajanian GK (1992) Elevated basal firing rates and enhanced responses to 8 -Br-cAMP in locus coeruleus neurons in brain slices from opiate-dependent rats. Eur J Pharmacol 211:47-53.

Krapivinsky G, Gordon EA, Wickman K, Velimirovic B, Krapivinsky L, Clapham DE (1995) The G-protein-gated atrial $\mathrm{K}^{+}$channel $\mathrm{I}_{\mathrm{KACh}}$ is a heteromultimer of two inwardly rectifying $\mathrm{K}^{+}$-channel proteins. Nature 374:135-141.

Lane-Ladd S, Pineda J, Boundy V, Pfeuffer T, Krupinski J, Aghajanian G, Nestler E (1997) CREB (cAMP response element-binding protein) in the locus ceruleus: biochemical, physiological, and behavioral evidence for a role in opiate dependence. J Neurosci 17:7890-7901.

Law P-Y, Wong Y, Loh H (2000) Molecular mechanisms and regulation of opioid receptor signaling. Annu Rev Pharmacol Toxicol 40:389-430.

Luscher C, Jan LY, Stoffel M, Malenka RC, Nicoll RA (1997) G protein-coupled inwardly rectifying $\mathrm{K}^{+}$channels (GIRKs) mediate postsynaptic but not presynaptic transmitter actions in hippocampal neurons. Neuron [Erratum (1997) 19:following 945] 19:687-695.

Nestler EJ (2001) Molecular neurobiology of addiction. Am J Addict 10:201-217.

North RA, Williams JT (1985) On the potassium conductance increased by opioids in rat locus coeruleus neurones. J Physiol (Lond) $364: 265-280$.

Oleskevich S, Clements JD, Williams JT (1993) Opioid-glutamate interactions in rat locus coeruleus neurons. J Neurophysiol 70:931-937.

Osborne PB, Williams JT (1996) Forskolin enhancement of opioid currents in rat locus coeruleus neurons. J Neurophysiol 76:1559-1565.
Pepper C, Henderson G (1980) Opiates and opioid peptides hyperpolarize locus coeruleus neurons in vitro. Science 209:394.

Picciotto MR, Wickman K (1998) Using knockout and transgenic mice to study neurophysiology and behavior. Physiol Rev 78:1131-1163.

Ressler KJ, Nemeroff CB (1999) Role of norepinephrine in the pathophysiology and treatment of mood disorders. Biol Psychiatry 46:1219-1233.

Signorini S, Liao YJ, Duncan SA, Jan LY, Stoffel M (1997) Normal cerebellar development but susceptibility to seizures in mice lacking $\mathrm{G}$ protein-coupled, inwardly rectifying $\mathrm{K}^{+}$channel GIRK2. Proc Natl Acad Sci USA 94:923-927.

Slesinger P, Stoffel M, Jan Y, Jan L (1997) Defective $\gamma$-aminobutyric acid type $\mathrm{B}$ receptor-activated inwardly rectifying $\mathrm{K}^{+}$currents in cerebellar granule cells isolated from weaver and Girk2 null mutant mice. Proc Natl Acad Sci USA 94:12210-12217.

Travagli R, Dunwiddie T, Williams J (1995) Opioid inhibition in locus coeruleus. J Neurophysiol 74:519-528.

Travagli R, Wessendorf M, Williams JT (1996) Dendritic arbor of locus coeruleus neurons contributes to opioid inhibition. J Neurophysiol 75:2029-2035.

Velimirovic BM, Koyano K, Nakajima S, Nakajima Y (1995) Opposing mechanisms of regulation of a G-protein-coupled inward rectifier $\mathrm{K}^{+}$ channel in rat brain neurons. Proc Natl Acad Sci USA 92:1590-1594.

Wang Y, Aghajanian G (1987) Excitation of locus coeruleus neurons by an adenosine $3^{\prime}, 5^{\prime}$-cyclic monophosphate-activated inward current: extracellular and intracellular studies in rat brain slices. Synapse $1: 481-487$.

Wickman K, Nemec J, Gendler SJ, Clapham DE (1998) Abnormal heart rate regulation in GIRK4 knockout mice. Neuron 20:103-114.

Wickman K, Karschin C, Karschin A, Picciotto M, Clapham D (2000) Brain localization and behavioral impact of the $G$ protein-gated $\mathrm{K}^{+}$ channel subunit, GIRK4. J Neurosci 20:5608-5615.

Wickman K, Pu W, Clapham D (2002) Structural characterization of the mouse Girk genes. Gene 284:241-250.

Williams JT, North RA (1984) Opiate-receptor interactions on single locus coeruleus neurones. Mol Pharmacol 26:489-497.

Williams J, Egan T, North R (1982) Enkephalin opens potassium channels on mammalian central neurones. Nature 299:74-77.

Williams JT, North RA, Tokimasa T (1988) Inward rectification of resting and opiate-activated potassium currents in rat locus ceruleus neurons. J Neurosci 8:4299-4306.

Williams JT, Christie MJ, Manzoni O (2001) Cellular and synaptic adaptations mediating opioid dependence. Physiol Rev 81:299-343.

Wimpey T, Chavkin C (1991) Opioids activate both an inward rectifier and a novel voltage-gated potassium conductance in the hippocampal formation. Neuron 6:281-289. 